\title{
Patient preferences for autonomy in decision making in asthma management
}

\author{
R J Adams, B J Smith, R E Ruffin
}

\begin{abstract}
Background-Lower patient preferences for autonomy in management decision making during asthma exacerbations have been associated with an increased risk for future hospital admissions. We sought to examine patient preferences for asthma self-management autonomy, and the clinical and psychosocial factors associated with autonomy preferences.

Methods-A cross sectional observational study was performed with data collected between June 1995 and December 1997 of 212 adult patients with moderate to severe asthma managed, at least in part, at two teaching hospitals. Subjects completed a survey of autonomy preferences, quality of life, clinical morbidity and health service use, asthma knowledge, self-efficacy, coping styles, and psychosocial measures.
\end{abstract}

Results-Patients preferred clinicians to assume the major role in most decision making about their management. However, patients wished to remain in control in choosing when to seek care and wanted to share decisions regarding initiating changes in medications during a moderate exacerbation. Multiple regression analysis showed that concerns about adverse effects of medications, education level, an active coping style, perceptions of the propensity of physicians to involve them in treatment decision making, and concerns about costs causing delays in seeking medical care were associated with preferences for autonomy in decision making. Autonomy preferences were not related to measures of concurrent clinical asthma control or health related quality of life.

Conclusions-In a group of patients with moderate to severe asthma, a high proportion of whom were from socioeconomically disadvantaged backgrounds, education level, perceived physician behaviour, cost barriers to care, and psychosocial factors (but not clinical asthma control or management) were related to patient preferences for autonomy in management decision making during asthma exacerbations. This has implications for asthma action plans and design of selfmanagement programmes.

(Thorax 2001;56:126-132)

Keywords: asthma; self-management; decision making; patient preference
Interventions to increase patient involvement in management decision making lead to better outcomes for a number of chronic illnesses such as diabetes. ${ }^{12}$ A recent meta-analysis found that optimal self-management of asthma, consisting of a combination of a written action plan for the use and adjustment of medications, self-monitoring, and regular carer review led to improved outcomes, including a reduction in hospital admissions. ${ }^{3}$ However, the ability to generalise the results of many of these controlled clinical trials to the broad community of asthma patients is open to question. Low participation rates of potential eligible subjects, ${ }^{4}$ high drop out rates, ${ }^{5}$ and difficulties in recruiting at risk subjects such as those with lower socioeconomic status or education ${ }^{4-9}$ have led some to suggest that those who persist with programmes are atypical of asthma sufferers in general. ${ }^{10}$

Despite these concerns, little research has been done to ascertain patient attitudes towards the current recommendations of consensus guidelines, which emphasise enhancing patient self-management through increased autonomy in decision making. ${ }^{11}{ }^{12}$ Gibson et al reported that asthma patients did not show strong preferences for having a major role in decision making ${ }^{13}$ although, in common with many other conditions, ${ }^{14}{ }^{15}$ they did wish to be fully informed about their illness. However, little is known about what factors may specifically predict or influence these attitudes in patients with asthma.

Ascertaining the factors that influence selfmanagement autonomy may have significant potential benefits in the management of asthma. We have previously shown that lower preferences for autonomy in decision making with regard to initiating treatment changes during an asthma exacerbation are associated with an increased risk for admission to hospital with asthma. ${ }^{16}$ Certain patient characteristics, such as younger age and higher educational level, have been associated in other illnesses with both the propensity of physicians to involve their patients in treatment decisions ${ }^{17}$ and also with patient desires for involvement in decision making. ${ }^{14}$ Defining patient characteristics that influence preferences for selfmanagement autonomy may help to tailor asthma education and self-management programmes to optimise treatment and outcomes. Patient control is not suitable for all individuals. ${ }^{18}$ It is not known whether some asthma patients at risk for higher morbidity — such as those with lower socioeconomic status-have lower preferences for self-management autonomy and hence whether action plans 
encouraging self-control over treatment may not be universally appropriate.

Using the Asthma Autonomy Preference Index (API), ${ }^{13}$ we have examined the issue of patient preferences for asthma selfmanagement autonomy in a group with moderate to severe asthma. We have investigated the relationship between autonomy preferences and a number of clinical and psychosocial measures as well as sociodemographic characteristics. We have also looked at the effect on autonomy preferences of patients' perceptions of the extent to which their physicians seek to involve them in decision making about treatment.

\section{Methods}

PROTOCOL

The data for this study came from patients participating in the Western Region Asthma Pilot Project (WRAPP), a longitudinal observational study of factors related to asthma outcomes in adult hospital based patients over a 12 month follow up period. The study methodology has been described previously. ${ }^{16}$ Data were collected between June 1995 and December 1997 from subjects attending two teaching hospitals in Adelaide, South Australia (population 1.2 million) for at least part of their asthma management. Consecutive adult subjects were recruited following attendances at either site in outpatient clinics and emergency departments, or hospital admissions for asthma. Subjects were eligible if thet had a physician's diagnosis of asthma together with evidence of an increase of at least $15 \%$ in forced expiratory volume in one second $\left(\mathrm{FEV}_{1}\right)$ after administration of bronchodilator medication ${ }^{11}{ }^{19}$ or evidence of bronchial hyperresponsiveness with a histamine challenge test. ${ }^{20}$ Informed consent was obtained from all subjects. Following enrolment, surveys were sent by post every three months to all subjects for self-administration. As we wanted to examine the effect on patient preferences following at least 12 months' contact with the two hospitals, the analysis presented here is a cross sectional study from the 12 month follow up survey only. However, similar results were obtained for the other study periods.

\section{AUTONOMY PREFERENCE INDEX (API)}

The asthma API was adapted by Gibson and colleagues ${ }^{13}$ from the API scale of Ende et al. ${ }^{14}$ It was designed to measure preferences for autonomy in decision making in a general sense, as well as the extent to which people prefer doctors or themselves to make specific management decisions in three clearly defined asthma clinical vignettes. ${ }^{13}$ These hypothetical situations correspond to a routine office visit for stable disease ("Stable"), an attack of moderate severity requiring increased medications and an unscheduled physician visit ("Moderate" attack), and a severe episode requiring hospitalisation and an admission to an intensive care unit ("Severe" attack). Responses to the asthma API are made using a five point Likert-type response scale to individual items, with the scale score being the average of summed responses to the 18 items. Scores are arranged so that a higher score indicates a greater desire for physician involvement in decisions or lower autonomy preference (a score of 5 indicating that the doctor alone should make decisions and 1 indicating that the patient alone should do so). The information seeking component of the API was not administered. In all previous studies the desire for information has been universally very high. ${ }^{131421}$ It was felt that minimal new information would be gained to offset the burden on the patient of answering further numbers of questions.

DEMOGRAPHIC DATA AND SOCIOECONOMIC

STATUS

The surveys included items on demographic data and socioeconomic status. Two items were included to identify personal perceptions of current economic circumstances related to their asthma-namely, whether individuals had experienced any financial difficulties over the past year, and whether costs had prevented or delayed seeking any asthma care that was needed.

ASTHMA STATUS

The clinical asthma status was categorised into three levels of mild, moderate, and severe according to the severity criteria published by the National Asthma Education and Prevention Program (NAEPP). ${ }^{12}$ To adjust for the effect of treatment on current clinical status, controller medication use was included in all analyses. Controller medication use was categorised based on the reported daily dose of inhaled corticosteroids. Where fluticasone was being used, it was weighted to be scored at double its actual dose for purposes of categorisation - for example, $100 \mu \mathrm{g}$ was given a weight of $200 \mu \mathrm{g}$.

\section{PHYSICIAN'S PARTICIPATORY DECISION MAKING}

(PDM) STYLE

Patient perception of the physician's PDM style was assessed as the aggregate of the following three questions: (1) "If there were a choice between treatments, would your doctor ask you to help him/her to make the decision?" (2) "How often does your doctor make an effort to give you some control over your treatment?" and (3) "How often does your doctor ask you to take some of the responsibility for your treatment?" 1722 Responses were given on a five point Likert-type response scale ranging from "definitely yes" to "definitely no" for item (1) and from "very often" to "not at all" for items (2) and (3). Variations in PDM style were scored according to the methods of Kaplan et $a l .{ }^{17}$

PSYCHOSOCIAL CHARACTERISTICS

A number of validated scales were used to measure different psychosocial characteristics of importance in asthma. Personal coping styles thought to be of importance in asthma were measured-including denial, active, and avoidance coping. ${ }^{23}$ Active coping strategies measured were predominantly behavioural- 
Table 1 Sociodemographic data of the study population $(n=212)$

\begin{tabular}{|c|c|c|}
\hline Variable & Category & $\%$ \\
\hline \multirow[t]{4}{*}{ Age } & $15-34$ years & 42 \\
\hline & $35-54$ years & 28 \\
\hline & $55-64$ years & 17 \\
\hline & $>65$ years & 13 \\
\hline Sex $(\%)$ & Female & 67 \\
\hline \multirow[t]{2}{*}{ Marital status (\%) } & Married/defacto & 61 \\
\hline & Separated/divorced/single & 39 \\
\hline \multirow{3}{*}{ Country of birth (\%) } & Australia (non-Aboriginal) & 64 \\
\hline & Australia (Aboriginal) & 2 \\
\hline & Other & 34 \\
\hline \multirow[t]{4}{*}{ Annual income level (\%) } & $<\mathrm{A} \$ 8000$ & 32 \\
\hline & $\mathrm{A} \$ 8000-20000$ & 29 \\
\hline & $\mathrm{A} \$ 20001-50000$ & 31 \\
\hline & $>\mathrm{A} \$ 50000$ & 8 \\
\hline \multirow[t]{2}{*}{ Principal income source (\%) } & Wages/salary & 46 \\
\hline & $\begin{array}{l}\text { Government } \\
\text { pensions/allowances }\end{array}$ & 54 \\
\hline \multirow[t]{3}{*}{ Education level (\%) } & $\leqslant 10$ years school & 46 \\
\hline & $>10$ years school & 26 \\
\hline & Some post school & 28 \\
\hline \multirow{2}{*}{ Employed (\%) } & Yes & 46 \\
\hline & No/retired & 54 \\
\hline
\end{tabular}

for example, "I have become more informed about my asthma" - and cognitive strategiesfor example, "I thought about what I needed to do for my asthma". ${ }^{23}$ A number of attitudes and behaviour regarding asthma medication were measured including the degree of concern regarding possible adverse effects of medications, self-reported general treatment adherence, ${ }^{23}$ and specific asthma medication dislikes. ${ }^{25}$ Other measures included the level of confidence or self-efficacy in managing asthma ${ }^{26}$ and indicators of perceived emotional social support and social participation. ${ }^{27}$ The five item Socially Desirable Response Set measure was used to control for the tendency of some people to bias their responses to be more socially acceptable. ${ }^{28}$

\section{STATISTICAL ANALYSIS}

Comparisons between each of the scenarios were made by means of analysis of variance (ANOVA). Internal consistency of the scales was assessed by Cronbach's alpha coefficient. Relationships between scales and with other variables were assessed using Pearson's product moment correlation for continuous variables and intraclass correlation for categorical variables. Given the large number of variables available for analysis, significance at the $p<0.10$ level provided the basis for inclusion of variables into multivariate models in a parsimonious manner. ${ }^{29}$ To assess which variables

Table 2 Asthma management and morbidity among the study population $(n=212)$

\begin{tabular}{lll}
\hline Variable & Category & \% population \\
\hline Current asthma status & Moderate & 45 \\
FEV $_{1}$ (\% predicted) & Severe & 55 \\
& $<60 \%$ & 29 \\
Inhaled corticosteroid dose $(\mu \mathrm{g} /$ day) $)$ & $60-80 \%$ & 39 \\
& $>80 \%$ & 32 \\
& 0 & 20 \\
Regular oral corticosteroids & $1-1000$ & 29 \\
Bronchodilator use & $1001-2000$ & 32 \\
& $>2000$ & 19 \\
& Yes & 12 \\
Possess written asthma action plan & $<$ Weekly & 28 \\
& $>$ Weekly but <daily & 23 \\
& $1-4$ times/day & 28 \\
& $>4$ times/day & 22 \\
\hline
\end{tabular}

$\mathrm{FEV}_{1}=$ forced expiratory volume in one second. were the most important predictors of decision making autonomy preferences, multiple linear regression analyses for the overall asthma API were conducted. The Moderate attack scenario closely resembles the situation usually addressed by current written asthma action plans, requiring a patient to make decisions in response to increased symptoms regarding initiating changes in medications and about when to seek medical care. ${ }^{12}$ To investigate whether different independent variables predicted preferences in Moderate attacks compared with the overall autonomy index, models were also developed for the Moderate attack scenario and for the rest of the index scores without the items from this section included. All variables found to be significant at the univariate stage were entered into the regression models. Insignificant variables were progressively omitted until satisfactory models were found. The models were examined for goodness of fit. ${ }^{29}$ Asthma control was estimated by grouping subjects into categories of severity defined by the NAEPP. ${ }^{11}{ }^{12}$ Use of asthma medication was estimated by use of inhaled corticosteroids, regular oral corticosteroids, bronchodilators, and other asthma medications such as salmeterol and theophylline. The groupings used for these variables correspond to the parameters shown in table 2 .

Approval of the study protocol was obtained from the ethics committees of both institutions.

\section{Results}

Of 343 individuals identified as eligible for enrolment, completed survey responses were received from 293 at baseline and 212 (72\% of responders) completed the 12 month surveys and were included in this analysis. Most of the 61 subjects lost to follow up declined to participate further in the study. There were no statistically significant differences for the groups with and without 12 month follow up when compared for age, sex, education, household income, baseline asthma status, medication use, or lung function. There were no significant differences between the eligible group who did not return baseline surveys and the study subjects when compared for age, sex, or lung function.

The sociodemographic and clinical characteristics of the study population are shown in tables 1 and 2. The mean (SD) age was 41 (19) years. All subjects currently had moderate or severe persistent asthma according to the criteria of the NAEPP guidelines. ${ }^{11}$ These patients reported using relatively intensive medication regimens compared with those described in community surveys. ${ }^{30} 31$ There was a relatively low level of formal education compared with that in the Australian population as a whole. ${ }^{32}$ There was also a relatively high proportion of income assistance with $54 \%$ receiving some form of government pensions or allowances compared with a national figure of $30 \% .^{32}$ Over half $(57 \%)$ reported having financial difficulties over the past year, and $40 \%$ indicated that concerns about costs had caused them to delay or avoid seeking care needed for their asthma in the previous 12 months. 
Table 3 Mean (SD) athma autonomy preference index (API) scores $^{\star}(n=212)$

\begin{tabular}{lll}
\hline & Asthma API & Cronbach alpha \\
\hline Stable follow up & $3.4(0.8)$ & 0.77 \\
Moderate attack & $3.1(0.9)$ & 0.81 \\
Severe attack & $3.9(0.9)$ & 0.85 \\
General autonomy & $3.3(0.8)$ & 0.82 \\
Total asthma API & $3.4(0.8)$ & 0.87 \\
\hline
\end{tabular}

*Maximum 5 = "Doctor alone should make decisions"; minimum 1 = "Patient alone should make decisions".

ASTHMA API SCORES

The mean scores for each exacerbation scenario, the general autonomy items, and the overall preference index are shown in table 3 . Each mean scale score indicated a tendency for patients to prefer clinicians to assume the major role in decision making. For Total autonomy only $37 \%$ of subjects indicated a preference for greater input than their physicians into treatment decisions. On only three of the 18 items did the mean scores show that patients preferred greater input than their physicians into making decisions (score of <3.0). All three items dealt with decisions concerning the timing and necessity of physician visits. Autonomy preferences were stable over 12 months with minimal score changes seen in any of the categories, and with intraclass correlation coefficients of $0.82-0.88$ for the different scales.

Overall, patients expressed significantly stronger preferences for self-management autonomy in the Moderate scenario than during a routine visit for stable disease or a more severe attack $(\mathrm{p}<0.001)$. In the Moderate situation $64 \%$ of subjects indicated a preference for more input than their physicians into management decisions. However, when these scenario items were considered individually, there was a stronger preference for autonomy about when to see a physician than for decisions regarding altering medications. There was a significant difference $(p<0.01)$ between scores for the item regarding who should decide whether a visit to see a physician was needed (2.0 (0.9)) compared with whether an increase in asthma controller therapy was needed (3.4 (1.0)) or whether oral corticosteroids were indicated (3.5 (1.0)). During a Severe attack requiring admission to hospital significantly weaker preferences for autonomy compared with the other scenarios were reported $(\mathrm{p}<0.0001)$. However, $26 \%$ of patients scored below 3 , indicating a desire for equal or greater participation than physicians in decision making even during a

Table 4 Multiple linear regression analysis of variables associated with stronger Total autonomy preferences *

\begin{tabular}{lll}
\hline & Mean (SE) $\beta \dagger$ & p value \\
\hline More concerns about adverse effects of medications & $0.38(0.08)$ & 0.00006 \\
Greater use of an active coping style $\ddagger$ & $0.31(0.08)$ & 0.0002 \\
Higher physician's participatory decision making style\# & $0.28(0.08)$ & 0.001 \\
Higher level of formal education & $0.21(0.08)$ & 0.01 \\
Concerns about costs cause delays in seeking care & $0.21(0.09)$ & 0.02 \\
\hline
\end{tabular}

^Stronger preferences indicate a greater desire for patients to make decisions.

†Standardised regression coefficient.

‡Active coping involves taking steps to become more informed and involved in asthma management.

\#Patients' rating of the propensity of physicians to involve them in treatment decision making. severe attack necessitating admission to an intensive care unit.

UNIVARIATE ANALYSIS

A number of variables were significantly associated with Total asthma API scores in univariate analysis $(\mathrm{p}<0.01)$. Stronger preferences for decision making (Total) were associated with more education $(r=0.32)$, more concerns about adverse effects of medications $(r=0.40)$, use of more active coping strategies $(r=0.30)$, a more positive evaluation of the impact of asthma on their lives (satisfaction with illness) $(r=0.24)$, greater self-efficacy in asthma management $(r=0.29)$, and patients' perceptions of the physicians' propensity to involve them in decision making (physician's PDM style) $(r=$ 0.29). These variables were also significantly associated with scores in a Moderate attack. There was also an association seen with age, younger patients expressing a greater desire for self-management autonomy $(p=0.01)$. In addition, possession of a written asthma action plan showed a significant positive association with higher autonomy preferences in a Moderate attack $(p=0.008)$. There were no significant associations with any indicators of clinical status or quality of life and any of the attack scenarios, or for the overall index.

\section{MULTIVARIATE MODELS OF DECISION MAKING} PREFERENCES

Multiple regression analysis showed that concerns about the adverse effects of medications, active coping strategies, perception of the physicians' PDM style, cost concerns that caused delays in seeking care, and education level were significantly associated with preferences for autonomy in decision making with regard to asthma management, adjusting for age (table 4 ). The model was able to explain $48 \%$ of the variance.

The model for the index minus the Moderate scores was not significantly altered from the original overall model. In the Moderate attack model education level was not significantly associated with preferences for control over decisions. The other variables identified in the Total autonomy model remained significantly associated, and this model could explain $42 \%$ of the variance. Possession of a written action plan or a history of previous hospital admissions did not contribute to the final model.

\section{Discussion}

The results of this study in patients with moderate to severe asthma from a diverse range of sociodemographic backgrounds indicate that, on average, individuals in this at risk group do not desire to be predominantly responsible for decisions regarding asthma management. These findings are similar to those found by Gibson et al who studied both community asthma sufferers and those following a recent hospital admission. ${ }^{13}$ Multivariate analysis showed that autonomy preferences were associated with patient characteristics such as attitudes regarding adverse effects of medication, active coping mechanisms for dealing with asthma, cost concerns, and the level of 
formal education. Aspects of the patient-doctor interaction-specifically, the extent to which patients perceive that their doctors seek to involve them in decision making - also showed a significant association with autonomy preferences. Possession of a written action plan was not associated in the multivariate analysis with autonomy preferences in the Moderate attack, which is the vignette that corresponds to their use.

Asthma management decisions can be complex and it is impossible to codify every contingency that patients might face in managing their asthma. The objectives of asthma management are the acquisition of sufficient knowledge to make sense of changing symptoms and lung function, together with the development of skills and a positive approach to problem solving ${ }^{33}$ which can be described as effective self-regulation. ${ }^{34}$ It is clear that these objectives remain unfulfilled in many instances. A pattern emerges from our data where patients regard making changes to medications in response to increased symptoms to be a negotiable issue to be decided with a predominant input from their doctor, and most would not initiate these changes without consultation. However, patients felt strongly that the decision as to what circumstances would initiate the process of consultation should be left up to them. This is so, regardless of whether the patient has been provided with a written asthma action plan outlining when and how to increase medication when symptoms worsen. This finding has important implications for the use of written action plans as a major tool of asthma self-management.

The practical significance of these results lies in the previous finding of an association between lower decision making autonomy preferences and a higher risk for asthma hospital admissions over the subsequent year, independent of the baseline level of asthma control and medication use. ${ }^{16}$ Delays in initiating appropriate changes in care in acute attacks have been cited as a factor in adverse asthma outcomes, including death..$^{35}$ To deal with this, two separate areas of decision making by patients may need to be addressed. The standard action plans currently in use will not be appropriate for all patients. Merely providing a written plan will not necessarily assist patients to initiate changes in medication during acute attacks unless the question of whether this will be done without consultation with a physician has also been specifically negotiated, rather than left unstated or implied. The clinician may need to decide, in negotiation with the patient, whether to emphasise the appropriate initiation of medication changes in response to an attack or to concentrate on the appropriate time to seek help as the major aspect of selfmanagement. Written action plans will need to be personalised to each patient. Our results suggest that active, problem focused copers with a high desire for control over management decisions will accept initiating treatment changes using standard action plans. Individuals with low autonomy preferences may need far more conservative action points with the focus on how and when to seek direct medical assistance. Easy access via telephone to a designated asthma educator or case manager, or to the physician, may be helpful for these individuals. This approach has been successfully integrated into some asthma management programmes. ${ }^{36}$ The asthma API may be useful in identifying which course is more appropriate in a particular individual, but this now needs to be validated in a prospective study. Whether expressed autonomy preferences reflect actual behaviour in clinical situations is unknown. There is evidence to show that, where responses to a hypothesised asthma attack scenario do not accurately reflect actual patient behaviour, the reality may be more worrisome than the simulation. ${ }^{37}$ Further research is needed to examine the link between expressed preferences and actual patient selfmanagement behaviour.

A second goal of this study was to provide some insight into what factors might be associated with autonomy preferences in patients with moderate or severe asthma. The results suggest an interplay between an individual's psychological make up and personal demographic circumstances. Formal education plays a key role and, when education is taken into account, the effect of age on autonomy preferences disappears. Education has been associated with autonomy preferences in other conditions $^{1438}$ but had not been previously examined in asthma patients. Cost concerns of patients that delayed treatment were an issue in both the Total scale and in the Moderate attack, emphasising the powerful influence economic circumstances exert over behaviour and attitudes in what may be regarded by clinicians as a relatively straightforward medical situation. Given the nature of the questions asked in this scenario, it is possible that these items may, for some people, be just inquiries of their perceived ability to afford the cost of the medicine. It would seem unlikely that patients will enthusiastically initiate increases in medications or seek medical advice if the cost implications of these actions weigh heavily in their assessment. ${ }^{39}$ The predominance of cost concerns over perceived financial difficulties on autonomy preferences may relate to differences in the priorities of some patients who have to make choices about spending options. The issue of whether there are other non-financial barriers to care was not explored in this study, and the potential influence on preferences for decision making autonomy of these factors is an area for future examination.

Individuals who expressed strong concerns about the adverse effects of medications also desired retaining autonomy over decision making. These patients also said that concerns about side effects stop them taking many asthma medications. Our data do not show whether the concerns held by patients were erroneous or unwarranted fears, or if they arose out of previous adverse experiences. From the perspective of pragmatically attempting to enhance appropriate self-management in exacerbations, whether these fears are unwarranted or not is less important than the realisation by 
clinicians that real fears exist and have a major influence on attitudes and behaviour in asthma management.

Interventions that encourage patients to negotiate treatment decisions with their doctor show improved outcomes in some chronic conditions. ${ }^{2}{ }^{40}$ A positive doctor-patient interaction has beneficial effects on patient adherence and behaviour in asthma. ${ }^{39}{ }^{41}$ Our results suggest a critical role for the attitude and behaviour of the doctor in fostering decision making independence. Proven techniques exist to improve communication, patient education, and involvement. ${ }^{34}$ The integration of these techniques into an intervention directed towards children with asthma has been associated with improved outcomes, including reduced hospital admissions. ${ }^{42}$ Although the measure of PDM style was based on patient report only, and not on observation of physicians, it can be argued that the perception of the patient is ultimately the only criterion by which the physician's efforts in this area can usefully be judged. Given that a large proportion of the variance in autonomy preferences was not explained by the wide range of variables considered here, it would seem that the only way a clinician can ascertain an individual's desire for involvement in decision making is by some form of direct inquiry. ${ }^{38}$ This may require a definite change in current practice, as eliciting patients' preferences and level of understanding are reported to be rare components of patient-physician discussions in primary care. ${ }^{44}$

The nature of the study sample, with all subjects having moderate to severe asthma, may limit the generalisability of these results. It is possible that a community sample with less severe asthma may express different levels of self-management autonomy preferences, although this was not found by Gibson et al. ${ }^{13} \mathrm{~A}$ recent representative population survey in the US found that up to two fifths of all adults with a physician's diagnosis of asthma had symptoms at a similar level as the subjects in this study. ${ }^{45}$ In addition, individuals with socioeconomic disadvantage may have different attitudes from those with higher socioeconomic status. Although the sample had a higher proportion of people with lower income and education than the general population, it was still diverse in terms of all the sociodemographic variables assessed. While acknowledging these limitations, a number of studies have shown that socioeconomically disadvantaged groups are at risk for adverse asthma outcomes, and hence ascertaining factors that influence acceptance of autonomy in self-management programmes in these people is important. It is possible that lower education may produce difficulties in responding to the questionnaires and produce biased results. However, there were no difficulties noted during the survey period, and the internal consistency measures did not suggest inconsistent patterns of responses as might be expected if there were major problems.

There seems little reason to suppose that an extreme "consumerist" approach to health care $^{46}$ is favoured by many patients with moderate to severe asthma. It appears that an approach that deals with self-management individually and in partnership with physicians is the preferred option for most patients and has the most chance of success. In the self-management of asthma the issue of how much autonomy patients want in decision making and how this is best accommodated will need to be directly addressed. The difficulty is that this will be demanding of both the time and the emotional and clinical resources of the attending clinicians.

Funding: This study was supported by the University of Adelaide and the South Australian Health Commission.

Dr Adams is a recipient of the Thoracic Society of Australia and New Zealand/Allen \& Hanbury's Respiratory Research Fellowship.

1 Kaplan SH, Greenfield S, Dukes K, et al. Effect of a joint physician-patient training program on health outcomes and interpersonal care. Clin Res 1993;41:541A

2 Greenfield S, Kaplan SH, Ware J Jr, et al. Patients' participation in medical care: effects on blood sugar control and quality of life in diabetes. $\mathcal{F}$ Gen Intern Med 1988;3:448-57.

3 Gibson PG, Coughlan J, Wilson AJ, et al. Self-management education and regular practitioner review for adults with asthma. Cochrane Review. Issue 4. Oxford: Update Software, The Cochrane Library, 1999.

4 Bolton MB, Tilley BC, Kuder J, et al. The cost and effectiveness of an education program for adults who have asthma. F Gen Intern Med 1991;6:401-7.

5 Yoon R, McKenzie DK, Bauman A, et al. Controlled trial evaluation of an asthma education programme for adults. Thorax 1993;48:1110-6.

6 Yoon R, McKenzie DK, Miles DA, et al. Characteristics of attenders and non-attenders at an asthma education attenders and non-attenders at an

7 Bailey WC, Richards JM, Brooks CM, et al. A randomized trial to improve self-management practice in adults with trial to improve self-management practice
asthma. Arch Intern Med 1990;150:1664-8.

8 Hilton S, Sibbald B, Anderson HR, et al. Controlled evaluation of the effects of patient education on asthma morbidty in general practice. Lancet $1986 ; 1: 26-9$.

9 Abdulwadud O, Abramson M, Forbes A, et al. Attendance at an asthma educational intervention: characteristics of participants and non-participants. Respir Med 1997;91:524-9.

10 Klingelhofer EL, Gershwin ME. Asthma self-management programs: premises, not promises. F Asthma 1988;25:89101 .

11 National Asthma Campaign. Asthma management handbook 1996. Melbourne: National Asthma Campaign, 1996.

12 National Asthma Education and Prevention Program. Guidelines for the diagnosis and management of asthma. Expert Panel Report 2. Publication No. 97-4051 Bethesda, MD: NIH/National Heart, Lung, and Blood Institute, 1997.

13 Gibson PG, Talbot PI, Toneguzzi RC. Self-management, autonomy, and quality of life in asthma. Chest 1995;107: 1003-8.

14 Ende J, Kazis L, Ash A, et al. Measuring patients' desire for autonomy: decision making and information-seeking preferences among medical patients. F Gen Intern Med 1989;4: 23-30

15 Ende J, Kazis L, Moskowitz MA. Preferences for autonomy when patients are physicians. F Gen Intern Med 1990;5: $506-9$.

16 Adams RJ, Smith BJ, Ruffin RE. Factors associated with hospital admissions and repeat emergency department visits for adults with asthma. Thorax 2000;55:566-73.

17 Kaplan SH, Gandek B, Greenfield S, et al. Patient and visit characteristics related to physicians' participatory decision characteristics related to physicians' particip
making style. Med Care 1995;33:1176-87.

18 Centers for Disease Control and Prevention. Vital and health statistics, national hospital discharge survey: annual summary, 1993. DHHS Publication No. PHS 95-1782. US Department of Health and Human Services, Public Health Service, National Center for Health Statistics, 1995.

19 American Thoracic Society. Standardization of spirometry 1987 update. Am Rev Respir Dis 1987;136:1285-98.

20 Sterk PJ, Fabbri LM, Quanjer PH, et al. Airway responsiveness. Standardized challenge testing with pharmacological, physical and sensitizing stimuli in adults. Report of Working Party Standardization of Lung Function Tests, European Community for Steel and Coal. Official Statement of the European Respiratory Society. Eur Respir 7 1993;16(Suppl):53-83.

21 Deber RB, Kraetschmer N, Irvine J. What role do patients wish to play in treatment decision making? Arch Intern Med 1996;156:1414-20.

22 Kaplan SH, Greenfield S, Gandek B, et al. Characteristics of physicians with participatory decision-making styles. Ann Intern Med 1996;124:497-504.

23 Sherbourne CD, Hays RD, Ordway L, et al. Antecedents of adherence to medical recommendations: results from the Medical Outcomes Study. F Behav Med 1992;15:447-68. 
24 Pilowsky I, Spence ND. Manual for the Illness Behaviour Ouestionnaire (IBO) 2nd ed. Adelaide, Australia: UniverQuestionnaire $(I B Q) .2$
sity of Adelaide, 1983.

25 Osman LM, Russell IT, Legge JS, et al. Predicting patient attitudes to asthma medication. Thorax 1993;48:827-30.

26 Schlosser M, Havermans G. A self efficacy scale for children and adolescents with asthma: construction and validation. f Asthma 1992;29:99-108.

27 Kaplan GA, Camacho T. Perceived health and mortality: a nine-year follow-up of the human population laboratory cohort. Am $\mathcal{F}$ Epidemiol 1983;117:292-304.

28 Hays RD, Hayashi T, Stewart AL. A five-item measure of socially desirable response set. Educ Psychol Measure 1989; 49:629-36.

29 Clayton D, Hills M. Statistical models in epidemiology. Oxford: Oxford University Press, 1993.

30 Marks GB, Burney PGJ, Premaratne UN, et al. Asthma in Greenwich, UK: impact of the disease and current Greenwich, UK: impact of the disease and cur

31 Adams R, Ruffin R, Wakefield $M$, et al. Asthma prevalence, morbidity and management practices in South Australia, morbidity and management practices in So

32 Australian Bureau of Statistics. Australia now: a statistical profile. Canberra: Commonwealth of Australia, 1999.

33 Ruffin RE, Wilson D, Southcott AM, et al. A South Australian population survey of the ownership of asthma action plans. Med F Aust 1999;171:348-51.

34 Clark NM, Gong M. Management of chronic disease by practitioners and patients: are we teaching the wrong things? $B M \mathcal{F} 2000 ; 320: 572-5$.

35 Campbell DA, Yellowlees PM, McLennan G. Psychiatric and medical features of near fatal asthma. Thorax 1995;50: $254-9$
36 Greineder DK, Loane KC, Parks P. Reduction in resource utilization by an asthma outreach program. Arch Pediatr Adolesc Med 1995;149:415-20.

37 Kolbe J, Vamos M, Fergusson W, et al. Determinants of management errors in acute severe asthma. Thorax 1998;53:14-20

38 Benbassat J, Pilpel D, Tidhar M. Patients' preferences for participation in clinical decision making: a review of published surveys. Behav Med 1998;24:81-8.

39 Kolbe J, Vamos M, Fergusson W, et al. Differential influences on asthma self-management knowledge and self-management behaviour in acute severe asthma. Chest 1996;110:1463-8.

40 Bonner S, Rivera R, Zimmermann BJ. Improving asthma management by focusing on families' self-regulatory phase. Am $\mathcal{F}$ Respir Crit Care Med 1997;155:A728.

41 Bosley CM, Fosbury JA, Cochrane GM. The psychological factors associated with poor compliance with treatment in asthma. Eur Respir f 1995;8:899-904.

42 Clark NM, Gong M, Schork A, et al. Impact of education for physicians on patient outcomes. Pediatrics 1998;101:831-6.

43 Clark NM, Gong M, Schork A, et al. A scale for assessing health care providers' teaching and communication behavior regarding asthma. Health Educ Behav 1997;24:245-56.

44 Braddock CH, Fihn SD, Levinson W, et al. How doctors and patients discuss routine clinical decisions. 7 Gen Intern Med 1997;12:339-45.

45 Asthma in America. Executive summary. Research Triangle, NC: GlaxoWellcome Inc, 1998.

46 Lupton D. Consumerism, reflexivity, and the medical encounter. Soc Sci Med 1997;45:373-81. 